Oliver, M. F. \& Boyd, G. S. (1955). Brit. Heart f. 17, 299.

Page, I. H. \& Menschick, W. (1932), F. biol. Chem. 97, 359.

Rabinowitz, J. L. \& Gurin, S. (1953). Biochim. biophys. Acta, ro, 345.

Rabinowitz, J. L. \& Gurin, S. (1954). F. biol. Chem. 208, 307.

Rice, L. I., Schotz, M. C., Alfin-Slater, R. B. \& Deuel, H. J. Jr. (I953). F. biol. Chem. $201,867$.

Rittenberg, D. \& Schoenheimer, R. (1937). F. biol. Chem. 121, 235.

Russ, E. M., Eder, H. A. \& Barr, D. P. (I95I). Amer. F. Med. nI, 468.

Schoenheimer, R. \& Breusch, F. (1933). F. biol. Chem. ro3, 439.

Siperstein, M. D., Chaikoff, I. L. \& Chernick, S. S. (195I). Science, Ir3, 747.

Srere, P. A., Chaikoff, I. L. \& Dauben, W. G. (1948). F. biol. Chem. 176, 829 .

Srere, P. A., Chaikoff, I. L., Treitman, S. S. \& Burstein, L. S. (1950). 7. biol. Chem. r82, 629.

Steiner, A., Kendall, F. E. \& Mathers, J. A. L. (r952). Circulation, 5, 605.

Tomkins, G. M. \& Chaikoff, I. L. (1952). F. biol. Chem. 196, 569 .

Tomkins, G. M., Chaikoff, 1. L. \& Bennett, L. L. (1952). F. biol. Chem. r99, 543.

Tomkins, G. M., Sheppard, H. \& Chaikoff, I. L. (1953). F. biol. Chem. 201, I37.

Waelsch, H., Sperry, W. M. \& Stoyanoff, V. A. (1940). F. biol. Chem. 135, 297.

Wainfan, E., Henkin, G., Rittenberg, S. C. \& Marx, W. (1954). F. biol. Chem. 207, 843.

Wüersch, J., Huang, R. L. \& Bloch, K. (1952). Y. biol. Chem. r95, 439.

\title{
Experimental cholesterol atherosclerosis
}

\section{By I. Rannie, Department of Pathology, King's College, University of Durham and Royal Victoria Infirmary, Newcastle upon Tyne}

Since Anitschkow ( $\mathrm{I}_{9} \mathrm{I}_{3}$ ) first produced cholesterol atherosclerosis in rabbits his experiments have been repeated by many investigators who, though confirming his original findings, have failed to agree in the interpretation of the condition. Briefly stated, the result of prolonged cholesterol feeding in rabbits, as far as the blood vessels are concerned, is the production of changes in their walls commencing after a latent period of from 3 to 6 weeks. The changes are essentially focal accumulations of lipid-bearing phagocytes in the intima which becomes progressively thicker and eventually shows evidence of fibrosis with degeneration and sometimes calcification in the deeper layers. The lesions thus closely resemble human atheroma.

\section{Interpretation}

Anitschkow, up to I933 (Anitschkow, I933), held that the lesions were produced by the infiltration of cholesterol from the plasma through the endothelium and that its focal distribution in the vessel wall was due to local differences in the permeability of the endothelium. Duff (1936), on the other hand, said that the initial lesions were in the media due to some unrecognized metabolic product, and that the site of the intimal lesion was determined by the medial damage.

The origin of the foam cells or lipophages which appear in the intima has been a matter of controversy. The majority of investigators have regarded them as local endothelial or connective-tissue cells which have picked up cholesterol and other lipids from the imbibed plasma; but Leary (194I, I949) looked on them as cells of the reticulo-endothelial system, most probably Küpfer cells, which have detached themselves from the sinusoidal walls of the liver and entered the circulation. $\mathrm{He}$ 
suggested that they pass through the pulmonary circulation and eventually escape from the blood stream by actively invading the aortic intima.

Experiments carried out in collaboration with Professor Duguid (Rannie \& Duguid, I953) gave results which we interpreted as largely confirming Leary's findings except for the method by which the lipophages gain entrance to the intima. We demonstrated that these cells, circulating in the blood, tended to adhere to the intima in small clumps and in due course became covered by endothelium so that they were passively embodied in the vessel wall (for illustrations see Rannie \& Duguid, I953). Here we have another example of the principle enunciated by Duguid ( 1952 ) that material deposited on the intimal surface becomes part of the intima by rearrangement of the endothelium. We must conclude, therefore, that in the cholesterol atherosclerosis of the rabbit the lipophages are but passive agents in the formation of the arterial lesion.

\section{Disposal of cholesterol}

The arterial lesions, however, are not the whole story, and it is noteworthy that Anitschkow (1914) devoted an article to the description of the lesions produced in the spleen and bone marrow. He demonstrated lipophages free in the splenic sinuses, and Bailey (1916) confirmed this finding, adding that the lungs and kidneys were also usually involved. The early investigators were, therefore, fully aware that the cholesterol was taken up by the cells of the reticulo-endothelial system and that with continued feeding the viscera-with the exception of the brain-became saturated with the material. It would thus appear that the rabbit has no means of metabolizing gross excesses of cholesterol which accumulate and are dealt with like other inert matter. This idea gains support from other work. For example, Cook \& McCullagh (1939) reported cholesterol-feeding experiments in the rat, guinea-pig and rabbit. In the rat, which is able to metabolize cholesterol, no hypercholesterolaemia developed, and accordingly they found few changes apart from increased lipid in the liver. In the guinea-pig, although the blood cholesterol was raised to a level comparable with that in the rabbit, no lipid lesions of any note were found in the aorta. Gye \& Purdy (r924) using colloidal silica showed that the reticulo-endothelial system became filled with this material and that eventually the vessels throughout the body were lined by foam cells. Hueper (I94I) produced similar results with macromolecular substances such as polyvinyl alcohol and methyl cellulose, and he explained the development of the vascular lesions on the grounds that the animals had not the necessary mechanism to metabolize these macromolecular substances. It may be concluded, therefore, that the cholesterol lesion, as far as the rabbit is concerned, is a pathological accumulation in the tissues of an unmetabolized foreign substance, similar in nature to a lipid-storage disease, or thesaurosis, as Hueper (r 94I) calls it.

\section{Permeability of the vessel wall}

These findings lead one to consider the function of the vessel wall in dealing with foreign material which the body cannot readily metabolize. It is possible to find in 
the literature reference to several examples of a mechanism whereby the vessels dispose of foreign substance. For instance Foot (1925) injected indian ink intravenously and found that particles came to lie in phagocytes in the pulmonary alveoli, and Wartman, Hudson \& Jennings (I95I) showed that small particles of filter-paper were cleared from the venous blood by direct penetration through the walls of the pulmonary arteries into the perivascular tissue. Barnard (1953, 1954) discussing experimental pulmonary embolism described the migration of material through the arterial wall, and in this connexion, too, we may recall the life cycle of certain of the parasitic worms, notably Ascaris and Ankylostoma duodenale, where the larval parasites are known to penetrate the pulmonary vessels and gain entrance to the bronchi in their migration to the intestinal tract.

Examination of the lungs of our experimental rabbits showed appearances which could be interpreted as representing this kind of clearance mechanism in relation to circulating lipophages. As can be seen in Pl. I, I quite large collections of lipophages are to be found in the adventitial tissue of some of the pulmonary arteries. These have penetrated the whole thickness of the vessel wall to reach this position, and in Pl. I, 2 one can see a group of lipophages actually in the media lying between apparently undamaged muscle bundles. P1. 2, I,2 show a segment of arterial wall in which can be seen intimal cushions of foam cells together with foam cells in the media and quite large adventitial collections. Thus, in one section the whole process is illustrated. Before we can assume our interpretation to be correct we must explain the well-known fact that the cholesterol lesions are localized and do not affect the vessel walls in a diffuse manner, and we find that there are probably several factors to be taken into account. If we assume that the lipophages are in the circulating blood, it is obvious that before they can adhere to the intima they must come in contact with it and this will occur only at sites of turbulent blood flow. Such sites will be found near branches and where there is relative fixation of a part of the artery wall as, for example, by a contiguous bronchus. It will be noticed that these positions correspond to the sites of naturally occurring atheroma. Another factor which may determine the site of an accumulation may be the structure and thickness of a particular vessel. Only occasionally does one find lipophages in the wall of a vein and equally rarely in a thin-walled arteriole although, as can be seen in Pl. 2, 3, adventitial collections may be found in relation to small arteries. This finding suggests that we must regard the focal accumulations as most likely to occur in the thicker-walled arteries where there is more tissue to penetrate and therefore a greater likelihood for the clearance mechanism to be clogged. With the overloading of this clearance mechanism the systemic circulation will be flooded with lipophages and thus lead to formation of lesions in the aorta and other vessels. The localization of the aortic lesions will again depend on local turbulences allowing the lipophages to come in contact with the intima and adhere to it, and it may well be that the more compactly arranged elastica of the aorta will render it more difficult for a clearance to be effected. Be that as it may, although few observers have noted it, large collections of lipophages are found in the adventitial tissue of the aorta and other large arteries. 


\section{Influence of heparin and other substances}

Recently it has been claimed that heparin (Graham, Lyon, Gofman, Jones, Yankley, Simonton \& White, I95I) and sulphated alginic acid (Gutmann \& Constantinides, I955) will inhibit cholesterol atherosclerosis in the rabbit. Examination of the results, however, shows that though the amount of atheroma of the aorta is reduced it is not completely abolished. Gutmann \& Constantinides in their experiments noted great splenomegaly, the spleen pulp being crowded with foam cells, and it would appear probable that the only result of the giving of these substances is to alter the distribution of the cholesterol accumulation. How heparin may act is not obvious but it may be more than mere coincidence that the lungs, which are the main site of the clearance mechanism, are the organs richest in heparin.

With regard to the interpretation of such experiments one must utter a word of caution. It does not appear to be generally realized that there may be very great individual variations between one rabbit and another in the response to apparently identical experimental conditions. Some may show large amounts of cholesterol in the spleen but others show little or none. Some show great accumulations of lipid in the renal medulla and others none, and of even greater importance are the variations in the arterial accumulations between rabbits in the same experimental series. Ignorance of these facts has led to many conflicting reports in the literature, a notable example being those dealing with the effect of choline. Himsworth(1938) showed clearly enough that choline has no effect on the cholesterolaemia in the rabbit, but this finding did not deter later investigators from assuming that choline prevented the development of atherosclerosis. It was not until adequately controlled experiments had once more been undertaken that the true state of affairs was appreciated.

\section{Relation to human atheroma}

We must now consider whether the experimental lesions in the rabbit's aorta which have been studied so extensively over the last half century throw much light on the human lesions. Before we do so, however, we must first consider what we are dealing with in man. As Duguid (1954) has indicated human atheroma may be of two types, one resulting from thrombosis with fatty changes occurring secondarily, and the other being of a primary fatty nature. The fatty lesions which are well seen in diabetes mellitus and in some congenital abnormalities of lipid metabolism may be analogous to the lesions in the rabbit but they are relatively unimportant because, as Duguid \& Robertson (1955) have emphasized, they are not usually associated with narrowing. The important lesions in man are those that have caused narrowing and therefore impairment of the circulation and this effect is seen only as a sequel to thrombosis. Indeed it can be argued that pure fatty changes, by interfering with the resilience of the wall, will lead to widening of the lumen rather than to narrowing and this fact accounts for the ectasia to be seen in the aorta of rabbits given cholesterol and in many of the human atheromatous arteries. The all-important lesion as far as human pathology is concerned is therefore thrombosis and it is noteworthy that it does not occur in the experimental rabbit even when quite large areas of vessel 

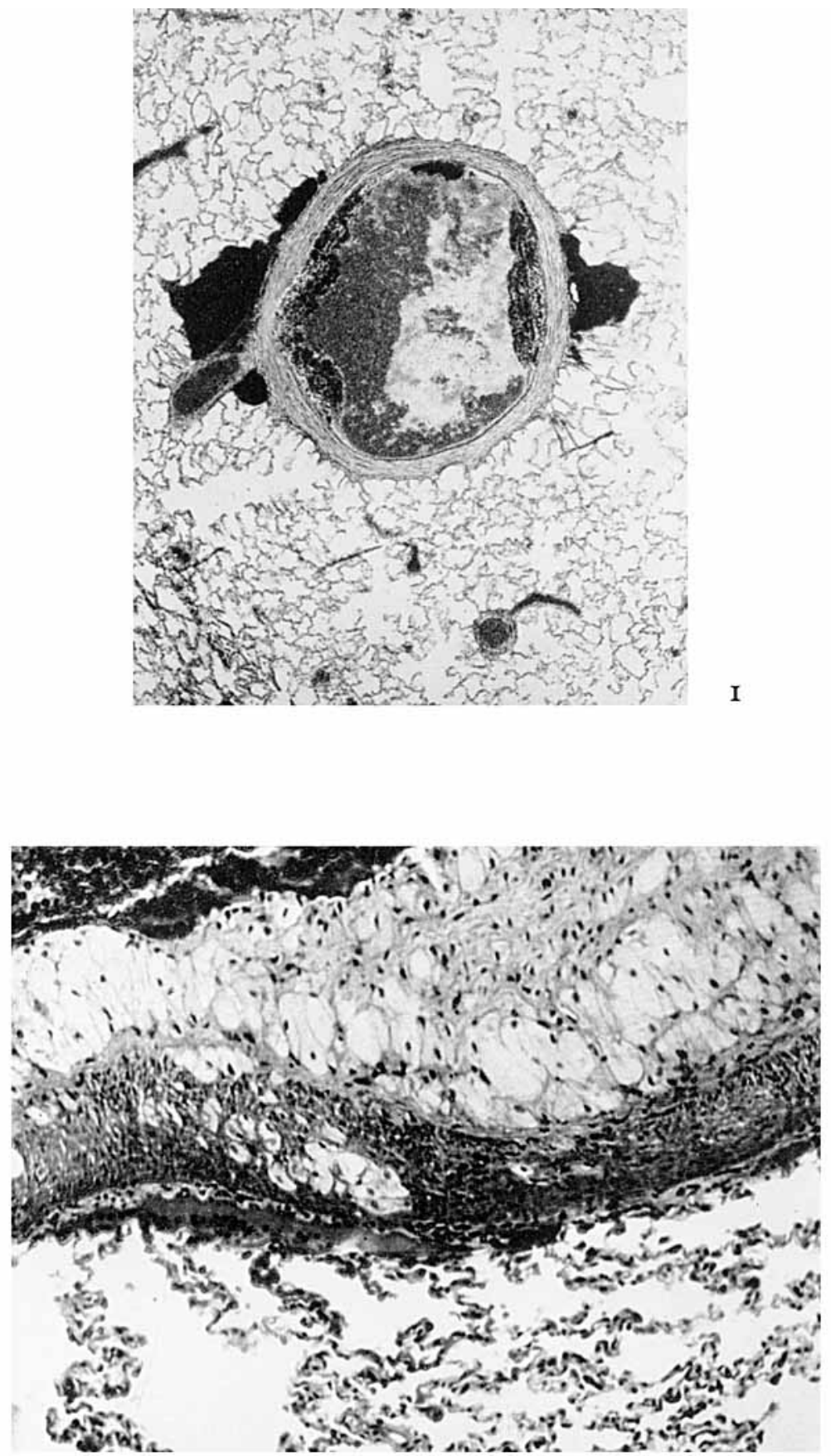

Proceedings of The Nutrition Society, Vol. I 5, No. I 

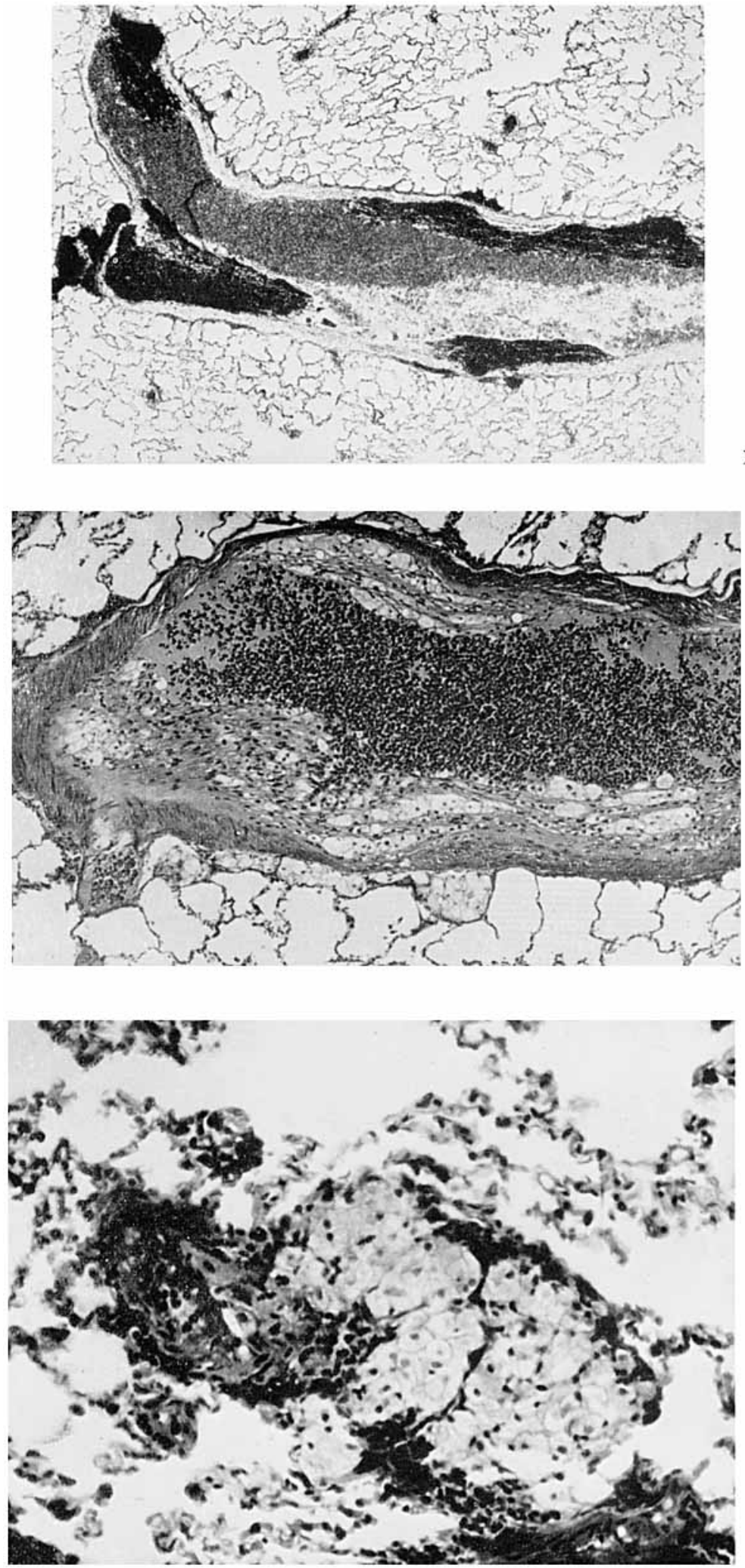

Proceedings of The Nutrition Society, Vol. I 5, No. I 
wall are apparently denuded of endothelium (Rannie \& Duguid, I953). In the chicken also, according to Katz \& Stamler (1953), every feature of human atheroma can be duplicated with the exception of thrombosis. It would seem, therefore, that, as far as human pathology is concerned, we should direct our attention to the study of factors governing the intravascular clotting of the blood, and so far no help has been forthcoming from experimental cholesterol feeding.

\section{SUMMARY}

The essential facts of experimental cholesterol atherosclerosis have been established for almost half a century but their interpretation is still in dispute. Consideration of the findings points to the condition being an example of a thesaurosis or pathological storage of inert material. It is shown that in this condition we find another example illustrating Duguid's (1952) principle that material deposited on the intima becomes incorporated in the vessel wall by a rearrangement of the endothelium. It is suggested that there is also illustrated the functioning of a mechanism by which foreign material is cleared from the blood stream by passing through the vessel walls from intima to adventitia.

Lastly it is emphasized that thrombosis is not produced in the experimental animals in this condition and that as thrombosis is the all important factor in the human lesion we cannot expect any help from the experiments in regard to elucidating the cause of coronary thrombosis.

\section{EXPLANATION OF PLATES}

PLATE I

I. Pulmonary artery.

Frozen section, Haematoxylin and Sudan IV. $\times 25$.

The dark areas in the adventitia represent collections of lipophages. These can also be seen forming intimal cushions.

2. Pulmonary artery.

Paraffin section, $\mathrm{H}$ and $\mathrm{E} . \times 230$.

Lipophages penetrating the media.

PLATE 2

I. Pulmonary artery.

Frozen section. Haematoxylin and Sudan IV. $\times 25$.

The darkly staining material represents lipophage accumulations which can be seen in all the coats of the artery.

2. Pulmonary artery.

Paraffin section. $\mathrm{H}$ and $\mathrm{E} . \times 90$.

Foam cells lying on the intima, being incorporated in the intima and penetrating the media to gain the perivascular tissues.

3. Pulmonary artery. Paraffin section, $\mathrm{H}$ and $\mathrm{E} . \times 230$.

Foam cell collection in the adventitial tissue of a small pulmonary artery. 


\section{REFERENCES}

Anitschkow, N. (1913). Beitr. path. Anat. 56, 379.

Anitschkow, N. (1914). Beitr. path. Anat. 57, 201.

Anitschkow, N. (1933). In Arteriosclerosis. [E. V. Cowdry, editor.] New York: The MacMillan Company.

Bailey, C. H. (I9r6). F. exp. Med. 23, 69.

Barnard, P. J. (1953). J. Path. Bact. 65, r29.

Barnard, P. J. (1954). Circulation, ro, 343.

Cook, R. P. \& McCullagh, G. P. (1939). Quart. F. exp. Physiol. 29, 283.

Duff, G. L. (1936). Arch. Path. 22, 16r.

Duguid, J. B. (1952). Lancet, 263, 207.

Duguid, J. B. (1954). Lancet, 266, $89 \mathrm{I}$.

Duguid, J. B. \& Robertson, W. B. (1955). Lancet, 268, 525.

Foot, N. C. (1925). Anat. Rec. 30, 15.

Graham, D. M., Lyon, T. P., Gofman, J. W., Jones, H. B., Yankley, A., Simonton, J. \& White, S. (195I). Circulation, 4, 666.

Gutmann, N. \& Constantinides, P. (1955). Arch. Path. 59, 717.

Gye, W. E. \& Purdy, W. J. (1924). Brit. F. exp. Path. 5, 238.

Himsworth, H. P. (1938). Acta. med. scand., Suppl. 90, ${ }_{5} 8$.

Hueper, W. C. (194I). Medicine, 20, 397.

Katz, L. M. \& Stamler, J. (1953). Experimental Atherosclerosis. Springfield: C. C. Thomas.

Leary, T. (1941). Arch. Path. 32, 507.

Leary, T. (1949). Arch. Path. 47, I.

Rannie, I. \& Duguid, J. B. (1953). F. Path. Bact. 66, 395.

Wartman, W. B., Hudson, B. \& Jennings, R. B. (195I.). Circulation, 4, 756.

\section{The relationship of lipaemia to thrombosis and atheroma}

\section{By H. W. Fullerton, Department of Medicine, University of Aberdeen}

The important arterial lesion which causes narrowing of the lumen and frequently leads to thrombosis with resultant obliteration is better termed 'atherosclerosis' than 'atheroma'. Duguid (r 949, 1952) has postulated that the pathogenesis of this disorder is fibrin formation or thrombosis, the fibrin or clot becoming covered by the endothelial lining of the intima and incorporated in the vessel wall. His work has been corroborated in important details by Crawford \& Levene (I952), and the evidence in favour of the hypothesis is convincing. Its acceptance entails a fundamental alteration in our conception of atherosclerosis, because the initial abnormalities probably reside in the plasma itself and are not to be sought primarily within the arterial wall.

Some years ago it occurred to us that lipaemia might be a factor responsible for intravascular fibrin formation and the initiation of atherosclerosis. Several considerations suggested this as a possibility. It was known that conditions associated with pathological lipaemia were accompanied by a high incidence of atherosclerosis; in this connexion, diabetes mellitus, the nephrotic syndrome, hypothyroidism and idiopathic hyperlipaemia come readily to mind. Conversely, there was the clinical impression that atherosclerosis was generally slight in the subjects of idiopathic steatorrhoea who would be protected against phases of alimentary lipaemia by impaired absorption of fat (Arnott, 1954). In addition, it had been clearly shown that a lipid factor was necessary for normal blood coagulation (Macfarlane, Trevan \& Attwood, 194I). 